\title{
Sickle cell retinopathy in Jamaican children: further observations from a cohort study
}

\author{
JOHN F TALBOT, ALAN C BIRD, GILLIAN H MAUDE, \\ ROBERT W ACHESON, BRENDAN J MORIARTY, AND \\ GRAHAM R SERJEANT
}

From the Medical Research Council Laboratories (Jamaica), University of the West Indies, Kingston, Jamaica

SUMMARY Serial retinal examinations were performed in children aged 5 years and older and fluorescein angiography/angioscopy in children 6 years and older participating in a cohort study of sickle cell disease. There were 1229 patient years of observation among 389 children aged 5-13 years. Peripheral retinal vessel closure was present in approximately $50 \%$ of children with SS and SC genotypes at age 6 years and increased to affect $90 \%$ of children by age 12 years. A matched pair analysis, comparing groups with minimal and complete closure, indicated that complete closure was associated with significantly lower total haemoglobin and fetal haemoglobin levels and significantly lower weight in SS disease, whereas in SC disease the risk factors appeared to be high mean cell volume and low platelet count. Proliferative retinopathy was rare, occurring only once in an 8-year-old boy with SC disease, despite 592 patient years of observation in children over this age.

The vaso-occlusive process of sickle cell disease affects the retinal vasculature, resulting in both nonproliferative and proliferative manifestations. The patterns, natural history, and risk factors for these changes have been extensively studied, but generally in patients presenting clinically with relatively advanced retinal disease. The early development of vascular changes, their risk factors, and their relationship to the formation of proliferative sickle retinopathy (PSR) remain largely unknown. A cohort study has provided a representative sample of children with sickle cell disease, and observations on the early development of ocular changes are reported.

\section{Materials and methods}

The children were part of a cohort study of sickle cell disease based on the screening of 100000 consecutive normal deliveries at the main Government Maternity Hospital (Victoria Jubilee Hospital). Between June 1973 and December 1981 this programme detected

Correspondence to Professor G R Serjeant, Medical Research Council Laboratories, University of the West Indies, Kingston 7, Jamaica, WI.
315 children with homozygous sickle cell (SS) disease, 201 with sickle cell-haemoglobin C (SC) disease, 33 with sickle cell-beta ${ }^{+}$thalassaemia (S beta $^{+}$thal) and 14 with sickle cell-beta ${ }^{0}$ thalassaemia (S beta ${ }^{0}$ thal). The diagnostic procedures ${ }^{1}$ and the methods of review ${ }^{2}$ have been reported.

Visual acuity was assessed as best corrected vision with Snellen's type or an illiterate E chart. Ophthalmoscopy through a dilated pupil was routinely performed in children aged 5 years and over. Fluorescein angiography/angioscopy was routinely performed in children aged 6 years and over unless ophthalmoscopy revealed changes requiring fluorescein study at an earlier age.

At the date of last assessment (January 1986) the children were aged 5-13 years. Retinal examinations had been performed at least once in $219 / 242$ (90\%) eligible children with SS disease, in 135/162 (83\%) eligible children with SC disease, in $24 / 30(80 \%)$ children with $\mathrm{S}$ beta $^{+}$thalassaemia, and in $11 / 12$ $(92 \%)$ children with $S$ beta $^{0}$ thalassaemia. Of these, fluorescein angiography/angioscopy had been performed at least once in $189 / 219(86 \%)$ with SS disease, in $124 / 135(92 \%)$ with SC disease, in all children with $\mathrm{S}$ beta ${ }^{+}$thalassaemia, and in $9 / 11(82 \%)$ children with $S$ beta ${ }^{0}$ thalassaemia. The numbers of 
children with $\mathrm{S}$ beta $^{+}$thalassaemia and $\mathrm{S}$ beta ${ }^{0}$ thalassaemia were too small to draw conclusions on the risk factors for retinal pathology in these genotypes, and this report is therefore confined to children with SS and SC disease.

Peripheral retinal vessel closure was diagnosed if there was continuing retinal non-perfusion extending posteriorly from the ora to at least the equator. The posterior extent of presumed closure proved too difficult to measure more accurately. The circumferential extent of closure was arbitrarily classified as minimal (less than $60^{\circ}$ closure in each eye), extensive (combined closure in both eyes exceeding $360^{\circ}$ ), and complete (entire periphery of both eyes affected).

Haematological indices were measured, as previously described, by means of electronic counters (Coulter Electronics). Fetal haemoglobin (HbF) was measured by alkali denaturation. ${ }^{3}$ Alpha thalassaemia was detected by restriction endonuclease analysis of DNA obtained from the buffy coat. ${ }^{4}$ Since the distributions of $\mathrm{HbF}$ and reticulocytes were skewed, the transformations $\log _{e}(\mathrm{HbF}+4)$ and $\log _{e}$ (reticulocytes +1 ) were used to give a more normal distribution prior to analysis.

\section{Results}

VISUAL ACUITY

The proportion of children with normal visual acuity (better than 6/12) increased with age, $57 \%$ at 5 years, $62 \%$ at 6 years, $71 \%$ at 7 years, $78 \%$ at 8 years, $77 \%$ at 9 years, to $80 \%$ at 10 years, most probably reflecting greater understanding and co-operation.

A visual acuity of $6 / 12$ or less was observed in at least one eye on one or more occasions in 17 children (12 SS, 5 SC). A child with acuity of less than $6 / 60$ had had pneumococcal meningitis with bilateral metastatic endophthalmitis and extensive chorioretinal atrophy. In two children acuities of $6 / 36$ were attributed to anisometropic amblyopia and to albinism. In the others (three children with $6 / 18,11$ with $6 / 12$ ), which were generally observed on only one occasion, no cause could be found.

\section{RETINAL PATCHES}

Retinal patches were circumscribed areas of discolouration in the peripheral retina generally with well defined borders. They were frequently but not always related to obvious vessels, and usually appeared in the plane of the retina. Some were darker and some lighter than the surrounding retina, probably representing the signs previously described as dark-without-pressure ${ }^{5}$ and white-withoutpressure. ${ }^{6}$ Some were grey-brown with iridescent spots resembling the previously reported mottled brown areas.' These were probably the sequel to intraretinal haemorrhage, though recent haemorrhages were seen infrequently.

These retinal patches occurred in a similar proportion of children with SS and SC disease and increased significantly $(p<0.05)$ from $20 \%$ at 5 years to $47 \%$ at 10 years in both genotypes combined. Between the ages of 6 and 10 years they were significantly $(p<0.05)$ more frequent in males in both genotypes. Analysis of the circumferential distribution of patches revealed a significant preponderance $(65 \%)$ on the temporal side.

\section{PERIPHERAL RETINAL VESSEL CLOSURE}

Prevalence. Fluorescein angiography was not performed before the age of 6 years unless retinal examination indicated abnormalities, so the proportion of children with closure is probably overrepresented at both ages 5 (range 4.5-5.4 years) and 6 (range 5.5-6.4 years). From age 7 years data are more representative, and the proportion of children showing either some closure or extensive closure on angiography increased between 7 and 12 years in both SS and SC disease (Fig. 1).

Closure was more common in SS than in SC disease between the ages 6 and 11 years and extensive closure

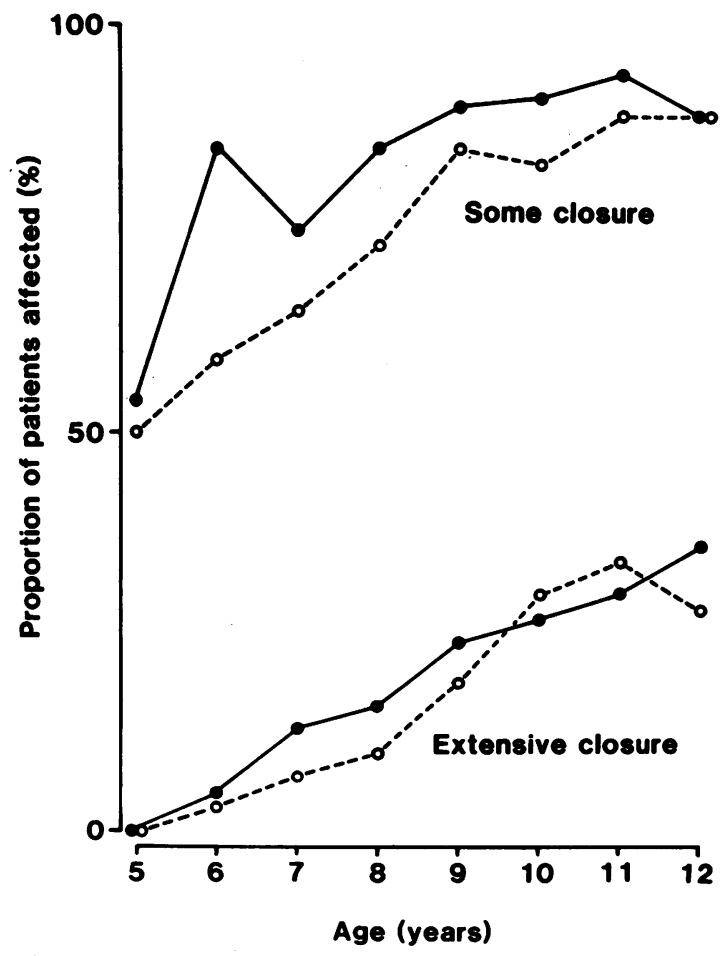

Fig. 1 Prevalence of peripheral retinal vessel closure at different ages in SS (-O) and in $S C\left(\mathrm{O}_{-} \mathrm{O}\right)$ disease. 
from age 6 to 9 years, though the differences did not reach statistical significance. Closure was more common in males in both SS and SC disease between the ages of 6 and 10 years, the sex difference within both genotypes being significant $(\mathrm{p}<0 \cdot 05)$ at 7 years but not at later ages. The degree of closure in both eyes was generally similar, a difference in circumferential grading of $120^{\circ}$ or more between eyes occurring in only $42 / 189(22 \%)$ patients with SS disease and in $25 / 124(20 \%)$ patients with SC disease.

Complete closure had occurred in 23 SS children (14 male, 9 female) and in $16 \mathrm{SC}$ children (13 male, 3 female). There was a preponderance of males among those with complete closure, the Mantel Haenszel $\chi^{2}$ test indicating a significant difference in SC disease $\left(\chi^{2}=5.44, \mathrm{p}<0.05\right)$ but not in SS disease $\left(\chi^{2}=0.41\right)$. The overall $\chi^{2}$ test for sex, taking account of genotype was significant $\left(\chi^{2}=4.64 ; p<0.05\right)$.

Incidence. Closure was present on first examination in $137 / 189(72 \%)$ SS children and in 68/124 (55\%) SC children, so that only the remaining 52 SS and $56 \mathrm{SC}$ children were available for prospective observations on the initial incidence of closure. In these cases closure was observed to develop for the first time in 29 SS and in 34 SC children between the ages of 7 and 12 years, the incidence being approximately constant across the age span and of a simliar order in both genotypes. At the last examination there was no closure in 23 children with SS disease (seven aged 10 years and over) and in 22 children with SC disease (eight aged 10 years and over).

Progression. Observations on the progress of closure were possible in all patients who had not attained complete closure, and annual assessments were possible over 325 patient years in SS disease and over 191 patient years in SC disease. Closure generally progressed gradually over several years from none to complete closure. Among a total of 118 patient years of observation commencing with no closure five patients (two SS, three SC) developed extensive closure within one year, and one of these, an SC male aged 7 years, progressed to complete closure. This rapid closure was not associated with dramatic clinical events and the child progressing to complete closure within one year appeared to be well throughout the year's observation.

Risk factors for closure. The possible role of some haematological and clinical features as determinants of closure was assessed in a matched pairs analysis comparing groups with complete closure and with none or minimal closure. There were 19 pairs of children with SS disease and 13 pairs with SC disease, all matched to within six months of age and having steady state haematology recorded within six months of the ophthalmological examination.

Patients with SS disease and complete closure had significantly lower levels of total haemoglobin and $\mathrm{HbF}$ (Table 1). Although earlier observations ${ }^{8}$ had suggested that the effect of haemoglobin was dependent on the effect of $\mathrm{HbF}$, analysis of variance in this study indicated independent effects of both total haemoglobin and $\mathrm{HbF}$. Patients with SC disease and complete closure had higher mean cell volumes (MCV) $(p<0.05)$ Weight was significantly lower among SS patients with closure, but there were no differences in height in either genotype (Table 2).

There were nine patients with SS disease and homozygous alpha thalassaemia, four of whom had no closure at last examination (ages $7,8,10$, and 12 years). Analysis at age 7 years, when data were

Table 1 Comparison of some haematological features in matched pairs of patients showing either minimal or complete peripheral retinal vessel closure

\begin{tabular}{|c|c|c|c|c|c|c|}
\hline \multirow[b]{2}{*}{ Variable } & \multicolumn{2}{|c|}{ Minimal $\left(<60^{\circ}\right)$ or no closure } & \multicolumn{2}{|c|}{ Complete closure } & \multicolumn{2}{|c|}{ Significance } \\
\hline & Mean & $S D$ & Mean & $S D$ & $t$ & $p$ \\
\hline \multicolumn{7}{|l|}{ SS disease ( $n=19$ pairs) } \\
\hline Haemoglobin (g/dl) & $8 \cdot 4$ & $1 \cdot 2$ & $7 \cdot 2$ & 0.8 & $-3 \cdot 91$ & $<0.001$ \\
\hline $\log _{e}(\mathrm{HbF}+4)$ & $2 \cdot 38(6 \cdot 8)$ & 0.41 & $2 \cdot 00(3 \cdot 4)$ & 0.30 & $-3 \cdot 77$ & $<0.001$ \\
\hline $\mathrm{MCHC}(\mathrm{g} / \mathrm{l})$ & 34.6 & $3 \cdot 2$ & $34 \cdot 5$ & $2 \cdot 8$ & $-0 \cdot 11$ & NS \\
\hline $\operatorname{MCV}(f 1)$ & $83 \cdot 7$ & $8 \cdot 0$ & $83 \cdot 5$ & $7 \cdot 5$ & -0.09 & NS \\
\hline $\log _{e}($ retics+1) & $2 \cdot 29(8 \cdot 9)$ & 0.49 & $2.53(11.6)$ & 0.34 & 1.43 & NS \\
\hline Platelets $\left(\times 10^{9} / 1\right)^{*}$ & 413 & 158 & 400 & 149 & 0.19 & NS \\
\hline \multicolumn{7}{|l|}{$S C$ disease $(n=13$ pairs $)$} \\
\hline Haemoglobin & $10 \cdot 7$ & $1 \cdot 4$ & $10 \cdot 8$ & 0.9 & $0 \cdot 37$ & NS \\
\hline $\log _{e}(\mathrm{HbF}+4)$ & $1 \cdot 66(1 \cdot 3)$ & 0.25 & $1 \cdot 63(1 \cdot 1)$ & 0.23 & $0 \cdot 34$ & NS \\
\hline $\mathrm{MCHC}(\mathrm{g} / \mathrm{l})$ & $35 \cdot 1$ & $2 \cdot 0$ & $35 \cdot 5$ & $1 \cdot 8$ & 0.47 & NS \\
\hline $\operatorname{MCV}(f 1)$ & $74 \cdot 3$ & $8 \cdot 9$ & $79 \cdot 4$ & 6.9 & 2.07 & $<0.05$ \\
\hline $\log _{e}($ retics +1$)$ & $1 \cdot 71(4 \cdot 5)$ & 0.34 & $1.68(4.4)$ & 0.42 & -0.28 & NS \\
\hline Platelets $\left(\times 10^{9} / 1\right) \dagger$ & 390 & 116 & 191 & 78 & $5 \cdot 07$ & $<0.01$ \\
\hline
\end{tabular}

*Based on 11 pairs. †Based on five pairs.

Figures in parentheses represent means re-expressed in original units. 
Table 2 Heights and weights in matched pairs of patients showing either minimal or complete peripheral retinal vessel closure

\begin{tabular}{|c|c|c|c|c|c|c|}
\hline \multirow[b]{2}{*}{ Variable } & \multicolumn{2}{|c|}{$\begin{array}{l}\text { Minimal }\left(<60^{\circ}\right) \\
\text { or no closure }\end{array}$} & \multicolumn{2}{|c|}{ Complete closure } & \multicolumn{2}{|c|}{ Significance } \\
\hline & Mean & $S D$ & Mean & $S D$ & $t$ & $p$ \\
\hline \multicolumn{7}{|l|}{ SS disease } \\
\hline $\begin{array}{l}\text { Age (years) } \\
\text { Weight (kg) }\end{array}$ & $\begin{array}{r}9 \cdot 4 \\
25 \cdot 2\end{array}$ & $\begin{array}{l}1.7 \\
3.8\end{array}$ & $\begin{array}{r}9 \cdot 5 \\
23 \cdot 3\end{array}$ & $\begin{array}{l}1 \cdot 7 \\
3.7\end{array}$ & -2.72 & $<0.05$ \\
\hline Height $(\mathrm{cm})$ & $129 \cdot 8$ & 8.9 & $128 \cdot 8$ & 8.9 & $1 \cdot 48$ & NS \\
\hline \multicolumn{7}{|l|}{ SS disease } \\
\hline Age (years) & $9 \cdot 8$ & $1 \cdot 3$ & $10 \cdot 0$ & $1 \cdot 4$ & - & - \\
\hline Weight (kg) & $25 \cdot 7$ & $4 \cdot 3$ & $27 \cdot 5$ & $4 \cdot 7$ & 1.09 & NS \\
\hline Height $(\mathrm{cm})$ & $131 \cdot 0$ & $9 \cdot 6$ & 135.4 & $9 \cdot 2$ & $1 \cdot 31$ & NS \\
\hline
\end{tabular}

available on $6 / 9$ patients with homozygous alpha thalassaemia, indicated that these patients were more likely to have normal eyes or minimal closure than those with a normal alpha globin gene number (Fisher's exact test, $\mathrm{p}=\mathbf{0 . 0 1}$ ). In SC disease the two patients with homozygous alpha thalassaemia had less closure, but the difference was not significant.

Proliferative retinopathy. A boy with SC disease is the only child with PSR to date. When assessed at ages 6 and 7 years he had peripheral retinal vessel closure in both eyes, more marked in the left. At $8^{1 / 2}$ years closure had extended in the right eye and there was a circumscribed leaking lesion (Fig. 2A) in the left temporal periphery at 4 o'clock. When he was reassessed eight days later perfusion had ceased (Fig. 2B). At 9 years closure had progressed to $360^{\circ}$ of both

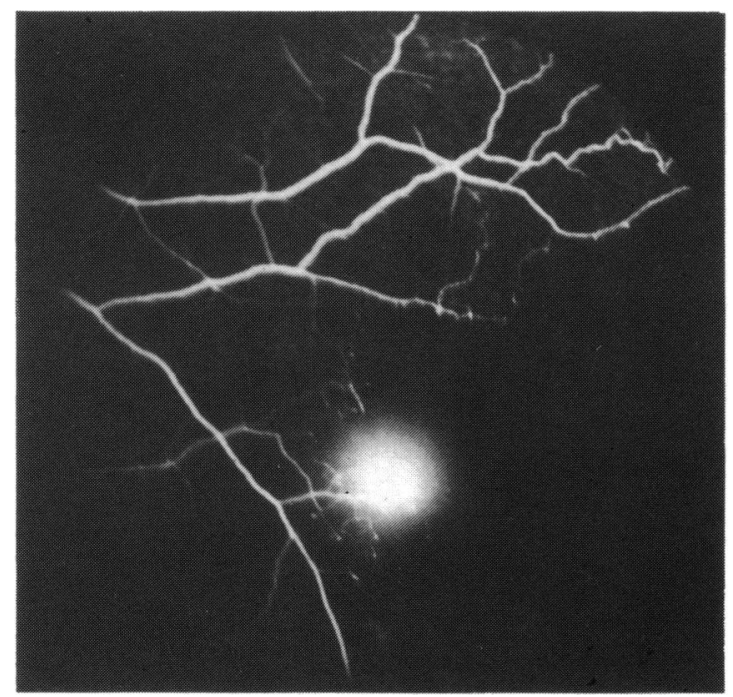

Fig. 2A Fluorescein angiogram of the left temporal periphery in an $81 / 2$-year-old male with SC disease showing small leaking PSR lesion.

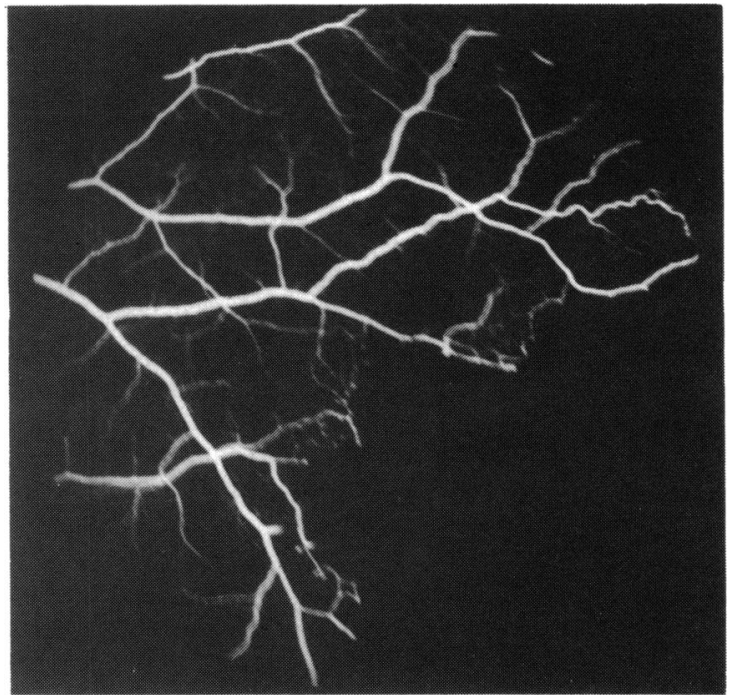

Fig. 2B Same area eight days later reveals spontaneous cessation of perfusion.

eyes, and the PSR lesion in the left periphery was reperfused and more extensive (Fig. 2C). At age 10 years this lesion had enlarged further (Fig. 2D) and PSR had developed in the other eye.

\section{Discussion}

The patient co-operation necessary for fluorescein angiography restricted its routine use until 6 years, by

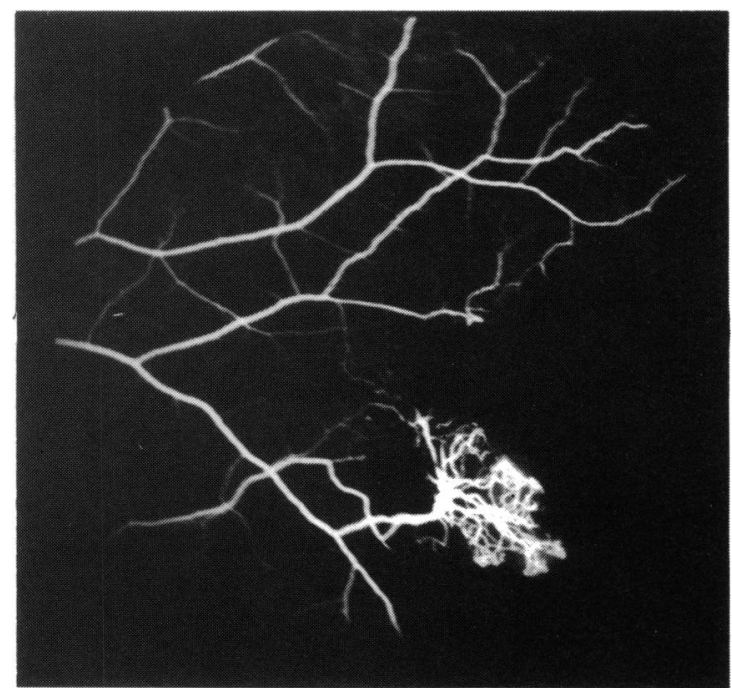

Fig. 2C Same area six months later indicated the PSR lesion is reperfused and has extended. 


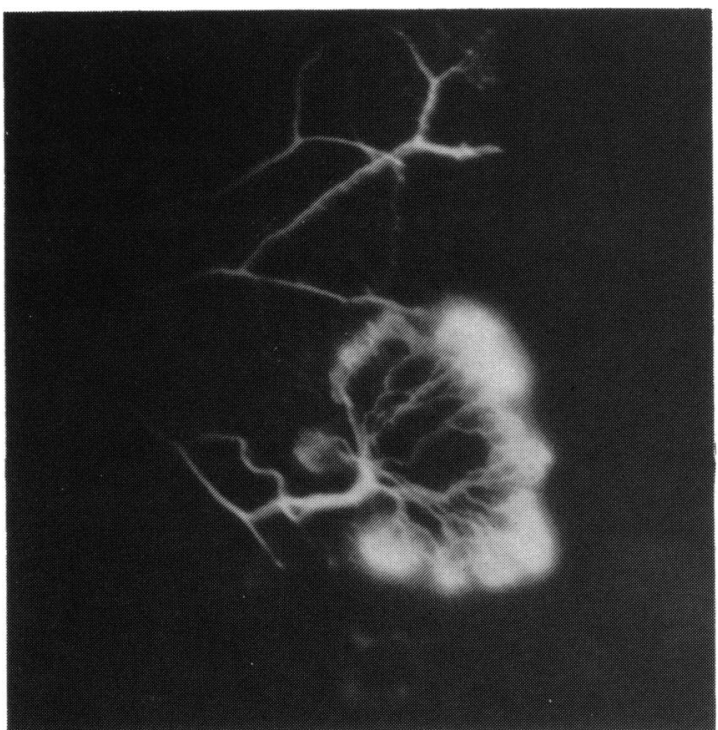

Fig. 2D Same area 18 months later illustrating extension of the PSR lesion.

which age over half of the study children had already developed peripheral retinal vessel closure. In these cases it was possible to make some observations on the progression of closure, and in the others the development of closure for the first time could be observed.

Age was a major determinant of retinal vessel occlusion, which generally manifested a steady progression, dramatic changes within one year being uncommon. Males of both genotypes were at significantly higher risk for developing retinal patches and vessel occlusion, although the mechanism was not clear. Total haemoglobin levels are significantly lower in males than in females with SS disease from ages 5 to 14 years, ${ }^{9}$ and males have slightly lower $\mathrm{HbF}$ levels, ${ }^{10}$ both indices being risk factors for closure in the matched pairs analysis. The significance of genotype, with an increased risk of closure in SS disease observed in an earlier study, ${ }^{8}$ was less apparent in the present more extensive data.

Matched pairs analysis indicated that a low total haemoglobin and low $\mathrm{HbF}$ were risk factors for complete closure in SS disease. A low $\mathrm{HbF}$ is generally associated with evidence of increased intravascular sickling" and has been incriminated in several vaso-occlusive complications in SS disease. The association of closure with a low total haemoglobin, although consistent with previous retinal observations, ${ }^{8}$ conflicted with observations in other presumed vaso-occlusive sequelae of SS disease. Thus avascular necrosis of the femoral head, ${ }^{12}$ proliferative sickle retinopathy, ${ }^{13}$ and painful crises ${ }^{14}$ all appear more common with high total haemoglobin levels, especially in association with a low HbF. A positive relationship between total haemoglobin and $\mathrm{HbF}^{15}$ suggests that the apparent effect of low total haemoglobin may be accounted for by the effect of a low $\mathrm{HbF}$. Analysis of variance indicated that this was indeed the case in an earlier study, ${ }^{8}$ but the present data suggested an effect of low haemoglobin independent of the low HbF. Homozygous alpha thalassaemia, though uncommon and affecting only $3 \%$ of the Jamaican population, appeared to protect against retinal vessel closure. This subdivision of SS disease is associated with a lowered intracellular haemoglobin concentration, consequent inhibition of sickling, a lower haemolytic rate, and an increased total haemoglobin level. The clinical consequences are not uniformly beneficial, but the current study suggests that homozygous alpha thalassaemia may be beneficial to peripheral retinal blood flow at this age.

Analysis of haematological risk factors in SC disease indicated that a high MCV and low platelet counts were significantly associated with complete closure. Both findings were unexpected and difficult to explain. Homozygous alpha thalassaemia may also protect against retinal closure in SC disease, though the effect failed to reach significance with the two patients available in this study.

The significance or pathological basis of retinal patches is not clear, though their coincident distribution with that of peripheral vaso-occlusion suggests that they may be the sequel to vaso-occlusive events. Pre- or intraretinal haemorrhages were occasionally observed to evolve into patches, so some if not all may represent schisis cavities or other sequelae of haemorrhage. It is well recognised that arteriolar occlusions may be transient and subsequent reperfusion be followed by extravasation of blood through the damaged arteriolar wall and a local retinal haemorrhage. In several patients with arteriolar occlusion in the present study, perfusion was reestablished without any detectable permanent damage in the peripheral capillaries. If arteriolar obstruction causes closure, it seems likely that recurrent occlusion may be necessary before permanent reduction of the capillary bed occurs. In the majority of children the peripheral vasculature was remarkably stable, with little evidence of the remodelling reported in adults. ${ }^{16}$

This hypothesis of a dynamically changing pattern of transient occlusion and reperfusion may explain the relatively slow development of PSR. Only one child, aged 8 years with SC disease, has developed PSR out of a total of 592 observations in patients aged 8 years and over. Even this patient demonstrated the transient perfusion of early PSR, though the abnormal vessels were reperfused and extended 
when seen one year later. It may be anticipated that the children in the cohort study are shortly to enter the period of rapid progression.

We thank Dr Douglas Higgs, of the MRC Molecular Haematology Unit in Oxford, for ascertainment of the alpha thalassaemia status of these children. The work was supported in part by the Wellcome Trust and in part by Comprehensive Sickle Cell Grant PHS HL 15168 from the National Heart, Lung, and Blood Institute, National Institutes of Health, Bethesda, Maryland.

\section{References}

1 Serjeant BE, Forbes M, Williams LL, et al. Screening cord bloods for detection of sickle cell disease in Jamaica. Clin Chem 1974; 20: 666-9.

2 Serjeant GR, Grandison Y, Lowrie Y, et al. The development of haematological changes in homozygous sickle cell disease: a cohort study from birth to 6 years. Br J Haematol 1981; 48: 53343.

3 Betke K, Marti HR, Schlicht I. Estimation of small percentages of foetal haemoglobin. Nature 1959; 184: 1877-8.

4 Higgs DR, Aldridge BE, Lamb J, et al. The interaction of alphathalassemia and homozygous sickle-cell disease. $N$ Engl J Med 1982; 306: 1441-6.

5 Nagpal KC, Goldberg MF, Asdourian G, Goldbaum M, Huamonte F. Dark-without-pressure fundus lesions. $\mathrm{Br} J$ Ophthalmol 1975; 59: 476-9.

6 Nagpal KC, Huamonte F, Constantaras A, Asdourian G, Goldberg MF, Busse B. Migratory white-without-pressure retinal lesions. Arch Ophthalmol 1976; 94: 576-9.
7 Condon PI, Serjeant GR. Ocular findings in homozygous sickle cell disease in Jamaica. Am J Ophthalmol 1972; 73: 533-43.

8 Talbot JF, Bird AC, Rabb LM, et al. Sickle cell retinopathy in Jamaican children: a search for prognostic factors. $\mathrm{Br} J$ Ophthalmol 1983; 67: 782-5.

9 Hayes RJ, Beckford M, Grandison Y, Mason K, Serjeant BE, Serjeant GR. The haematology of steady state homozygous sickle cell disease: frequency distributions, variation with age and sex, longitudinal observations. Br J Haematol 1985; 59: 36982.

10 Mason KP, Grandison Y, Hayes RJ, et al. Post-natal decline of fetal haemoglobin in homozygous sickle cell disease: relationship to parental HbF levels. Br J Haematol 1982; 52: 455-63.

11 Serjeant GR. Irreversibly sickled cells and splenomegaly in sickle-cell anaemia. Br J Haematol 1970; 19: 635-41.

12 Hawker H, Neilson H, Hayes RJ, Serjeant GR. Haematological factors associated with avascular necrosis of the femoral head in homozygous sickle cell disease. Br J Haematol 1982; 50: 29-34.

13 Hayes RJ, Condon PI, Serjeant GR. Haematological factors associated with proliferative retinopathy in homozygous sickle cell disease. Br J Ophthalmol 1981; 65: 29-35.

14 Baum KF, Dunn DT, Maude GH, Serjeant GR. The painful crisis of homozygous sickle cell disease: a study of risk factors. Arch Intern Med 1987; 147: 1231-4.

15 Maude GH, Hayes RJ, Serjeant GR. The haematology of steady state homozygous sickle cell disease: interrelationships between haematological indices. Br J Haematol 1987; 66: 549-58.

16 Galinos SO, Stevens TS, Lee CB, et al. Spontaneous remodelling of the peripheral retinal vasculature in sickling disorders. Am J Ophthalmol 1975; 79: 853-70.

Accepted for publication 17 August 1987. 